\title{
Effects of Plasma Etching Chemistry and Post-Processing on the Mechanical Adhesion and Electrical Contact of Double Polysilicon Layer Structures
}

Yuan Xiong Li, Student Member, IEEE, Patrick J. French, and Reinoud F. Wolffenbuttel, Member, IEEE

\begin{abstract}
Double polysilicon layer structures separated by a silicon nitride layer are frequently used as structural multilayers in surface micromachining. In this paper the effect of three types of plasma etching chemistries for nitride patterning and postprocessing on the characteristics of both mechanical adhesion and electrical contact resistance between the two polysilicon layers is investigated. It was found that all three chemistries yielded good mechanical adhesion between the two polysilicon layers. Both the chemistry based on $\mathrm{CF}_{4} / \mathrm{SF}_{6}$, with a poor selectivity $(0.7)$ of etching nitride over the underlying polysilicon layer, and the chemistry based on $\mathrm{CHF}_{3} / \mathrm{CF}_{4}$, with a selectivity of 3 , provided good electrical contact. The chemistry based on $\mathbf{C H F}_{3} / \mathbf{N}_{2}$, which yielded a selectivity of 15 , on the other hand, resulted in a polymer film between the two polysilicon layers, resulting in electrical insulation. This polymer film can be effectively removed by using post-processing, which involves in-situ oxygen plasma treatment. Therefore, a chemistry such as that based on $\mathrm{CHF}_{3} / \mathrm{CF}_{4}$ can be applied when the lower polysilicon thickness allows a moderate selectivity, whereas the $\mathrm{CHF}_{3} / \mathbf{N}_{2}$ chemistry is favored when high-selectivity is required. The latter, however, requires in-situ post-processing.
\end{abstract}

\section{INTRODUCTION}

$\mathbf{S}$ URFACE micromachining is a major technology for fabricating micromechanical structures for sensors and actuators [1]. In applications such as micromotors [2] and tuneable light interferometers [3], double polysilicon layer structures with both good mechanical adhesion and electrical contact in-between are required. Often the intermediate layer is an insulating film such as silicon nitride or silicon dioxide. This layer is patterned with plasma etching before the deposition of the upper polysilicon layer to provide contact between the two polysilicon layers. Plasma etching is preferred due to its capability of etching very fine features resulting from the etching anisotropy. Since the lower polysilicon layer is exposed to plasma when the insulating layer is etched through, etching chemistry must be carefully chosen to obtain a high selectivity between the etched film and underlying polysilicon layer. This is required to maintain the integrity of the polysilicon layer. Using a chemistry which etches the insulating film, while producing an etch-inhibiting layer on the

Manuscript received December 13, 1993; revised June 6, 1994. The review of this paper was arranged by Associate Editor S. D. Senturia.

The authors are with the Laboratory for Electronic Instrumentation, Department of Electrical Engineering, Delft University of Technology, $2628 \mathrm{CD}$ Delft, The Netherlands.

IEEE Log Number 9406764. surface of the lower polysilicon layer, is a common practice in plasma etching [4]. Therefore, it is expected that both the etching chemistry and post-processing after etching can have a significant influence on the surface quality of the lower polysilicon layer and, therefore, on the mechanical adhesion and electrical contact of the double polysilicon layer structures. However, sucl an influence has received little attention in literature on plasma etching.

The mechanical adhesion and electrical contact between two polysilicon layers through contact windows in silicon nitride have been investigated in this research by using three different plasma etching chemistries for the etching of the silicon nitride; these are $\mathrm{CF}_{4} / \mathrm{SF}_{6}, \mathrm{CHF}_{3} / \mathrm{CF}_{4}$, and $\mathrm{CHF}_{3} / \mathrm{N}_{2}$ based chemistries. A post-processing of in-situ oxygen plasma treatment after the nitride etching was also used. It is shown that the upper polysilicon layer adhered well to the lower polysilicon layer, independent of the etching chemistry and post-processing. The $\mathrm{CF}_{4} / \mathrm{SF}_{6}$-based chemistry has a poor selectivity ( 0.7$)$ of etching nitride over the underlying polysilicon layer and it provides good electrical contact between the two polysilicon layers. The chemistry based on $\mathrm{CHF}_{3} / \mathrm{CF}_{4}$ yields a selectivity of 3 and a good electrical contact. The chemistry based on $\mathrm{CHF}_{3} / \mathrm{N}_{2}$ results in a polymer film between the two polysilicon layers, which insulates them. This polymer formation impedes etching and thus leads to a very high etching selectivity of 15 . However, this film causes high contact resistance and thus post-processing is required to remove it. Therefore, to form a double polysilicon layer structure with good mechanical adhesion and electrical contact between the two layers, a chemistry such as the one based on $\mathrm{CHF}_{3} / \mathrm{CF}_{4}$ is suitable because it has reasonable selectivity, while forming only little polymer film. If very high etching selectivity is required, a chemistry such as the one based on $\mathrm{CHF}_{3} / \mathrm{N}_{2}$ would be favorable although post-processing after plasma etching is essential to remove the polymer film from the lower polysilicon layer.

\section{EXPERIMENTS}

The starting material was $4^{\prime \prime}(100)$ p-type wafers with a resistivity of $2-5 \Omega \mathrm{cm}$. After $1000 \AA$ thermal oxide growth, a low-stress polysilicon layer [5] of $1400 \AA$ was deposited in a Tempress LPCVD system (Model OMEGA M) by $\mathrm{SiH}_{4}$ decomposition and doped by phosphorus ion implantation of 
TABLE I

Plasma Etching Conditions and Post-Processing for 3 Groups of Wafers

\begin{tabular}{|c|c|c|c|}
\hline Group & Type & Etching chemistry for the nitride & $\begin{array}{l}\text { Post-process after } \\
\text { the nitride etching }\end{array}$ \\
\hline \multirow[t]{2}{*}{1} & $\mathbf{A}$ & \multirow{2}{*}{$\begin{array}{l}\mathrm{CF}_{4}(70 \mathrm{sccm})+\mathrm{SF}_{6}(10 \mathrm{sccm}) \\
+\mathrm{O}_{2}(10 \mathrm{sccm})\end{array}$} & No \\
\hline & $B$ & & Yes \\
\hline \multirow[t]{2}{*}{2} & A & \multirow{2}{*}{$\begin{array}{l}\mathrm{CHF}_{3}(25 \mathrm{sccm})+\mathrm{CF}_{4}(25 \mathrm{sccm}) \\
+\mathrm{He}(40 \mathrm{sccm})\end{array}$} & No \\
\hline & B & & Yes \\
\hline \multirow[t]{2}{*}{3} & A & \multirow[t]{2}{*}{$\mathrm{CHF}_{3}(5 \mathrm{sccm})+\mathrm{N}_{2}(45 \mathrm{secm})$} & No \\
\hline & B & & Yes \\
\hline
\end{tabular}

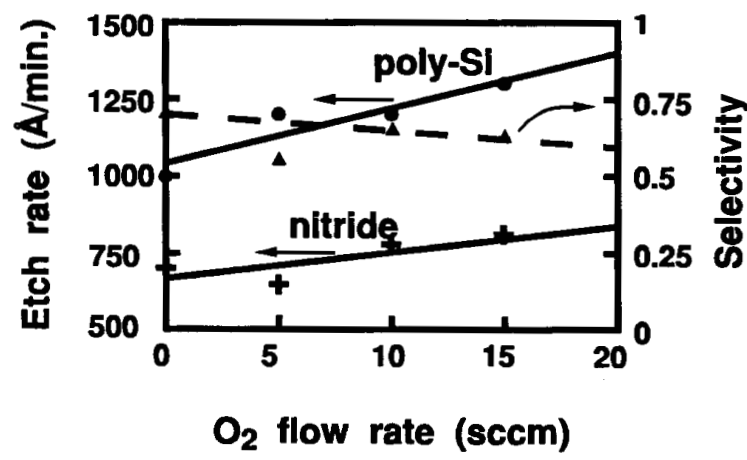

Fig. 1. The dependence of etch rate and selectivity on the $\mathrm{O}_{2}$ content in the $\mathrm{CF}_{4} / \mathrm{SF}_{6} / \mathrm{O}_{2}$ chemistry. The processing parameters were: $\mathrm{CF}_{4}=70 \mathrm{sccm}$, $\mathrm{SF}_{6}=10 \mathrm{sccm}, \mathrm{RF}$ power $=60 \mathrm{~W}$, pressure $=37.5 \mathrm{mtorr}$.

$80 \mathrm{keV}, 5 \times 10^{15} \mathrm{~cm}^{-2}$, followed by an annealing at $850^{\circ} \mathrm{C}$ for 30 minutes in $\mathrm{N}_{2}$ atmosphere. The resulting sheet resistance of the polysilicon layer was approximately $200 \Omega / \square$. Subsequently a 1700 - $\AA$-thick low-stress silicon nitride layer was deposited in a Tempress LPCVD system (Model OMEGA M) by using reaction of $\mathrm{SiH}_{2} \mathrm{Cl}_{2}$ with $\mathrm{NH}_{3}$. The nitride layer was patterned by plasma etching described below, to provide the contact windows for the two polysilicon layers. A $1.3-\mu \mathrm{m}$ thick HPR204 photoresist was used for the mask during the nitride plasma etching. Some samples were subjected to an in-situ oxygen plasma after the plasma etching of the nitride layer. Control wafers were wet etched in $20 \% \mathrm{HF}$ solution. Then wafers were dip-etched in BHF solution for 30 seconds before the deposition of the second polysilicon layer of $1400 \AA$, doped and annealed as the first polysilicon layer. For comparison, the dip-etching was not carried out before the second polysilicon deposition in a group of control wafers subjected to the same processing sequences. After patterning of the second polysilicon, the sheet resistance of the polysilicon layer and electrical contact resistance between the two polysilicon layers were measured with Van der Pauw test structure and Kelvin test structure [6], respectively, using HP4145B semiconductor parameter analyzer. The mechanical adhesion of the two polysilicon layer was examined using scanning electron microscope, model Philips SEM525M.

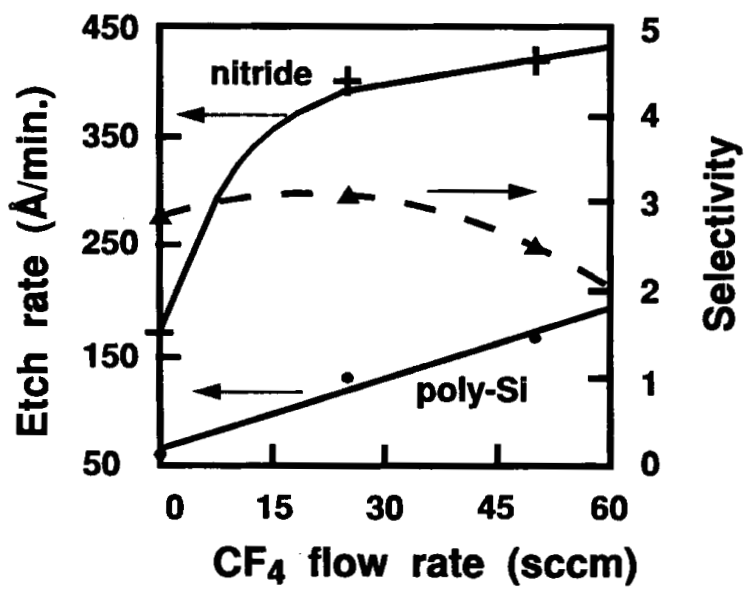

Fig. 2. The etch rate and selectivity versus $\mathrm{CF}_{4}$ flow rate in the $\mathrm{CHF}_{3} / \mathrm{CF}_{4} / \mathrm{He}$ chemistry. The processing parameters were: $\mathrm{CHF}_{3}=25 \mathrm{sccm}$, $\mathrm{He}=40 \mathrm{sccm}, \mathrm{RF}$ power $=60 \mathrm{~W}$, pressure $=37.5 \mathrm{mtorr}$.

Plasma etching was carried out in a commercial parallel plate Reactive Ion Etching (RIE) machine (Alcatel GIR300). The applied RF power of $13.56 \mathrm{MHz}$ and the chamber pressure were fixed at $60 \mathrm{~W}$ and $37.5 \mathrm{mtorr}$, respectively, for all the etching experiments. Both the upper and lower electrodes of the RIE machine are $15 \mathrm{~cm}$ in diameter, with $6.5 \mathrm{~cm}$ distance between them. This electrode configuration leads to a power density of $0.34 \mathrm{~W} / \mathrm{cm}^{2}$. Three types of chemistry were used to etch the silicon nitride film. The first was $\mathrm{CF}_{4}(70 \mathrm{sccm})+\mathrm{SF}_{6}$ $(10 \mathrm{sccm})+\mathrm{O}_{2}(10 \mathrm{sccm})$; the second, $\mathrm{CHF}_{3}(25 \mathrm{sccm})+\mathrm{CF}_{4}$ $(25 \mathrm{sccm})+\mathrm{He}(40 \mathrm{sccm})$; and the third, $\mathrm{CHF}_{3}(5 \mathrm{sccm})+$ $\mathrm{N}_{2}(45 \mathrm{sccm})$. The post-processing was performed in-situ with $\mathrm{O}_{2}$ plasma $(50 \mathrm{sccm})$ after the nitride etching. The etch rate for the polysilicon and silicon nitride layers was determined by the thickness change (measured using a Leitz MPV-SP optical measurement system) divided by etching time. After the RIE etching, the remaining photoresist was removed in a barrel-type plasma asher (Technics Plasma GmbH Tepla plasma ashing system) using $\mathrm{O}_{2}$ and Ar gas mixture. Table I summarizes the plasma etching conditions and post-processing for three different groups of wafers.

\section{Results on Plasma Etching Selectivity OF THE NITRIDE OVER POLYSILICON}

The $\mathrm{CF}_{4} / \mathrm{SF}_{6} / \mathrm{O}_{2}$ chemistry for the etching of the first group of wafers resulted in non-selective etching of the nitride over the polysilicon. Fig. 1 shows nitride and polysilicon etch rate with the gas mixture when oxygen is varied from $0 \mathrm{sccm}$ to $15 \mathrm{sccm}$. Both etch rates increase with increasing oxygen content. However, the etch rate for the nitride remains lower than that for polysilicon at any oxygen content. Therefore, nitride cannot be selectively etched under these conditions. A flow of $10 \mathrm{sccm} \mathrm{O}_{2}$, used in this work, yielded a selectivity of only 0.7 .

Fig. 2 shows the etch rates for polysilicon and nitride with the gas mixture of $\mathrm{CHF}_{3} / \mathrm{CF}_{4} / \mathrm{He}$ for the etching of the second group of wafers when $\mathrm{CF}_{4}$ is varied from $0 \mathrm{sccm}$ to $50 \mathrm{sccm}$. With $25 \mathrm{sccm} \mathrm{CF}_{4}$, a selectivity of 3 was obtained. 


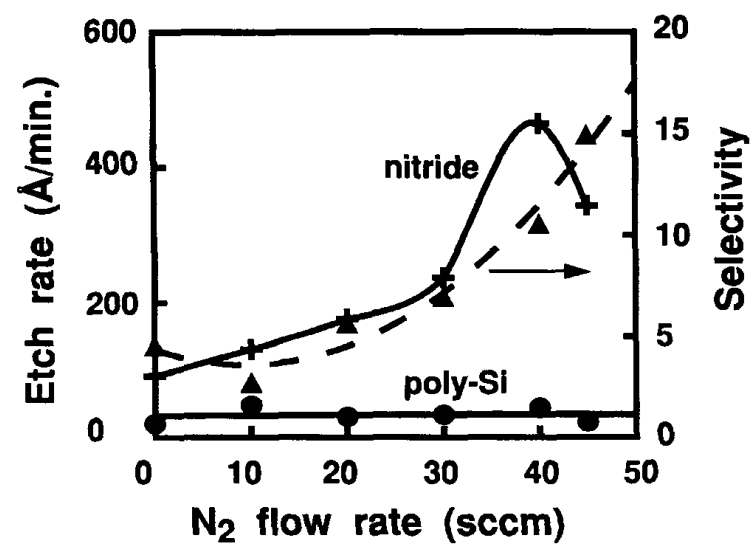

Fig. 3. The etch rate and selectivity versus $\mathrm{N}_{2}$ flow rate in the $\mathrm{CHF}_{3} / \mathrm{N}_{2}$ chemistry for a total flow rate of $0 \mathrm{sccm}$ to $50 \mathrm{sccm}$. The RF power and pressure were $60 \mathrm{~W}$ and 37.5 mtorr, respectively.

A selectivity of 15 was achieved using the $\mathrm{CHF}_{3} / \mathrm{N}_{2}$ chemistry for the etching of the third group of wafers. Fig. 3 shows the etch rate with the gas mixture when the nitrogen is varied from $0 \mathrm{sccm}$ to $45 \mathrm{sccm}$. It can be seen that the etch rate for the nitride increased monotonically in the range of $0-40 \mathrm{sccm}$, while that for the polysilicon was basically unchanged, yielding a selectivity which increases with $\mathrm{N}_{2}$ content.

To account for the non-uniformity of both the nitride etch rate and thickness, a $10 \%$ overetching time was added to the calculated etching time according to the average film thickness and etch rate. This overetching time resulted in an etching of the underlying polysilicon layer with the three different chemistries of about 300,60 , and $15 \AA$, respectively.

The process of plasma etching follows five stages [4]:

1) Transportation of reactive species from plasma to the substrate surface;

2) Adsorption of the reactive species to the substrate surface;

3) Chemical reaction of the species with the substrate material;

4) Desorption of the reaction product from the substrate surface;

5) Removal of the reaction product from the system.

Any one of the five stages can be rate-limiting, depending on etching chemistry and substrate material. In a $\mathrm{CF}_{4}$-based chemistry, such as used in the etching of the first group of wafers, $F$ atoms are well known to be the main reactive species for both silicon nitride and polysilicon etching [7]. The major rate-limiting step in the chemistry is stage three, i.e., the chemical reaction of the $\mathrm{F}$ atoms with silicon atoms. When the oxygen is added to the plasma, the concentration of the $\mathrm{F}$ atoms is greatly increased. This is due to the reaction between the oxygen atoms and the fluorocarbon species in the plasma, which would otherwise combine with the F atoms [7]. Therefore, both the etch rate of polysilicon and nitride increase with oxygen addition in the experiment.
The higher etch rate for the polysilicon as compared to that for the nitride, as shown in Fig. 1, is due to the lower activation energy for the reaction of $F$ atoms with silicon $(0.13 \mathrm{eV})$ than that with silicon nitride $(0.18 \mathrm{eV})$ [8]. Therefore, the chemistry for the etching of the first group of wafers provided no selectivity between the nitride and polysilicon etching. Note that the original thickness of the polysilicon layer is $1400 \AA$. The etching of the lower polysilicon during the overetching of the nitride with this chemistry ( $300 \AA$ ) amounts to about $22 \%$ of the original thickness, which is obviously unacceptable.

In a $\mathrm{CHF}_{3}$-based chemistry, such as used in the etching of the second group of wafers, $\mathrm{CHF}_{3}$ is known to decompose to generate abundant polymer-forming radicals such as $\mathrm{CF}_{2}$ [9]. These species can deposit and form a polymer layer on the substrate, inhibiting the chemical reaction of reactive species such as $\mathrm{F}$ atoms with the substrate atoms. Therefore, the ratelimiting stages in such a chemistry are both stage two and three, i.e., adsorption and chemical reaction of the reactive species. Many researchers have reported the polymer film formation on the silicon surface with $\mathrm{CHF}_{3}$-based plasmas [10]-[12]. It is also known that photoresist covering wafer surface plays a very important role in the polymer film formation. Indeed it was found that the etch rate of the polysilicon layer is about 3 times higher with $\mathrm{Al}$ mask than with the resist mask when the $\mathrm{CHF}_{3} / \mathrm{N}_{2}$ chemistry is used in our experiments. Photoresist generally consists of resin, which is a compound of carbon and hydrogen. During the plasma etching, photoresist is also etched by reactive species such as $\mathrm{F}$ atoms. The carbon-containing reaction products can help to form C-F polymer film by providing more precursors in the system. Since about $80 \%$ of the die area is covered by the photoresist in our test structures, a significant influence of the photoresist on the polymer formation would be expected. It is this polymer film that results in an etch rate of the silicon much lower than that in a $\mathrm{CF}_{4}$-dominant chemistry. However, when silicon nitride is exposed to $\mathrm{CHF}_{3}$-based chemistry, with the help of high energy ion bombardment, nitrogen atoms will be released from the nitride surface and react with the fluorocarbon radicals on the nitride surface, thus reducing the fluorocarbon film thickness [9]. Furthermore, the nitride can also be etched by species other than $\mathrm{F}$ atoms, such as $\mathrm{CF}_{3}$ [10]. This results in the selective etching of the nitride over polysilicon in the experiments.

When the $\mathrm{CF}_{4}$ is added to the gas mixture of $\mathrm{CHF}_{3} / \mathrm{He}$, used for the etching of the second group of wafers, more atomic fluorine is available for the etching. Meanwhile, the concentration of polymer-forming radicals is reduced due to their recombination with $F$ atoms. As a result, both etch rates for the nitride and polysilicon increase as is confirmed by Fig. 2. The $25 \mathrm{sccm} \mathrm{CF}_{4}$ content chosen for the etching chemistry for the second group of wafers gives a maximum selectivity of 3 .

When nitrogen gas is added to a $\mathrm{CHF}_{3}$ plasma, nitrogen atoms are generated, because of ionizing collision of $\mathrm{N}_{2}$ with high energy electrons in plasma. The nitride etch rate increases with nitrogen content in the gas mixture of $\mathrm{CHF}_{3} / \mathrm{N}_{2}$ for etching of the third group of wafers, as indicated in Fig. 3. 
Nitrogen gas is suspected to have a two-fold effect on the etching of the nitride. The first effect is dilution; this reduces the concentration of the polymer forming radicals, which in turn reduces the thickness of the fluorocarbon layer on the nitride film. Therefore the adsorption and chemical reaction of $F$ atoms (stages two and three) are enhanced. The second effect is the breaking down of nitrogen molecules into separate nitrogen atoms through interaction with energetic electrons in the plasma. These generated atoms diffuse to the nitride surface and combine with nitrogen atoms of the nitride which remain on the surface after removal of the adjacent silicon atoms [13]. The enhanced nitrogen concentration on the surface facilitates the formation of $\mathrm{N}_{2}$ molecules and thus enhances the desorption of reaction product (stage four). However, because the etch rate for the polysilicon remained basically unchanged with the nitrogen addition, it seems that the first effect is not sufficiently effective in the polysilicon etching. This conclusion is supported by resistance measurement results discussed in the next section.

\section{RESUlts ON CONTACT RESISTANCE AND POLYMER FILM FURMAIION}

It was found that the contact resistance between the two polysilicon layers is very high $\left(2 \sim 5 \times 10^{6} \Omega\right.$ on a $4 \times$ $4 \mu \mathrm{m}^{2}$ window at $100 \mathrm{~V}$ ) in the wafers without dip-etching before the second polysilicon deposition, irrespective of nitride etching history (wet or plasma etching using the three different chemistries). The poor electrical contact is most probably due to the native oxide layer on the first polysilicon layer. The contact exhibited breakdown characteristics when the applied voltage was above $100 \mathrm{~V}$, after which the contact resistance was about $200 \Omega$, which is further indication that the problem was due to a thin oxide layer. Therefore, dip-etching was essential to obtain a good electrical contact between the two polysilicon layers. Table II shows the measurement results of the contact resistance between two polysilicon layers via a $4 \times 4 \mu \mathrm{m}^{2}$ hole. These values are averaged measurements over 10 randomly selected dice. Note that the contact resistance measurement for the wafers with dip-etching before the second polysilicon deposition was carried out with $5-\mathrm{V}$ voltage, which is much lower than the voltage value for the same measurement for the wafers without dip-ctching.

From Table II it can be concluded that:

1) For groups one and two, there is little difterence (less than $6 \%$ ) in the contact resistance between type $\mathrm{A}$ and type B, as defined in Table I. For group three the contact resistance for type A exceeded the measurement range $\left(>10^{12} \Omega\right)$ whereas for type B the resistance is slightly higher than that of groups one and two.

2) All the contact resistances for type $B$ of the three groups are essentially the same as that of the control group, although there appears to be a slight increase in contact resistance with increasing etch selectivity.

The value of the contact resistance is a measure of the surface quality of the lower polysilicon layer. Contact resistance depends on the materials forming the contact, doping level, and
TABLE II

Measured Contact Resistance

\begin{tabular}{|c|c|c|c|c|c|c|c|c|}
\hline \multirow{2}{*}{\multicolumn{2}{|c|}{$\frac{\text { Group }}{\text { Type }}$}} & \multicolumn{2}{|c|}{1} & \multicolumn{2}{|c|}{2} & \multicolumn{2}{|c|}{3} & \multirow{3}{*}{\begin{tabular}{|l|} 
Control \\
89
\end{tabular}} \\
\hline & & \multirow{2}{*}{\begin{tabular}{|l} 
A \\
80
\end{tabular}} & \multirow{2}{*}{\begin{tabular}{|l|} 
B \\
85
\end{tabular}} & \multirow{2}{*}{$\begin{array}{l}\text { A } \\
89\end{array}$} & \multirow{2}{*}{\begin{tabular}{|l|} 
B \\
93
\end{tabular}} & \multirow{2}{*}{\begin{tabular}{|l} 
A \\
$\sim 10^{12}$
\end{tabular}} & \multirow{2}{*}{\begin{tabular}{|l|} 
B \\
100
\end{tabular}} & \\
\hline Contact & mean & & & & & & & \\
\hline \multirow[t]{2}{*}{$\begin{array}{c}\text { resistance } \\
\text { (I) }\end{array}$} & $\begin{array}{l}\text { standard } \\
\text { deviation }\end{array}$ & 3.11 & 3.19 & 4.45 & 1.74 & & 5.55 & 4.77 \\
\hline & $\begin{array}{l}\text { Without } \\
\text { dip- } \\
\text { etching }\end{array}$ & $2 \times 10^{6}$ & $4 \times 10^{6}$ & $2 \times 10^{6}$ & $5 \times 10^{6}$ & $2 \times 10^{6}$ & $2 \times 10^{6}$ & $3 \times 10^{6}$ \\
\hline
\end{tabular}

quality of the contact interface. For all the wafers the materials are identical. Although a slight difference in surface doping level may result from the difference in the overetching of the lower polysilicon, the implantation for the upper polysilicon ensures this difference is negligible. Therefore, any difference in the contact resistance indicates a difference in contact interface quality. During the nitride plasma etching, radiation damage caused by high energy ion bombardment and polymer formation on the surface are two major factors, apart from the etching of the underlying polysilicon due to insufficient selectivity, that modify the quality of the contact interface. Since the radiation damage can be removed effectively by high temperature annealing, which is performed after the ion implantation of the upper polysilicon layer, any increase in the contact resistance can safely be assumed to originate from thin film formation on the lower polysilicon surface during the plasma etching.

The above results show that there is no measurable polymer film formation, as far as contact resistance is concerned, for both groups one and two. As discussed in Section III, the $\mathrm{CF}_{4} / \mathrm{SF}_{6} / \mathrm{O}_{2}$ etching chemistry for the group-one wafers is unlikely to have created any fluorocarbon layer on either nitride or polysilicon surface. Although the reasonably high selectivity indicates that a polymer layer has been formed on the surface of the lower polysilicon layer with the $\mathrm{CHF}_{3} / \mathrm{CF}_{4} / \mathrm{He}$ chemistry for the etching of group-two wafers, this polymer layer is probably sufficiently thin or it has been removed during the plasma ashing to remove the remaining photoresist after the nitride etching. Therefore, the contact resistance is basically independent of post-processing since the polymer layer is automatically removed.

The extremely high contact resistance of the type A of group three suggests that significant polymer film is formed on the surface of the polysilicon when the nitride is etched through with the $\mathrm{CHF}_{3} / \mathrm{N}_{2}$ chemistry. This polymer layer is thick enough to become an insulating layer between the two polysilicon layers. Although the wafers were cleaned after the plasma etching using the barrel-type oxygen plasma asher to remove photo-resist followed by cleaning in $100 \%$ $\mathrm{HNO}_{3}$ for 5 minutes and $65 \% \mathrm{HNO}_{3}$ for 15 minutes, the polymer film appears not to have been removed. Further measurements showed that the contact exhibited breakdown 


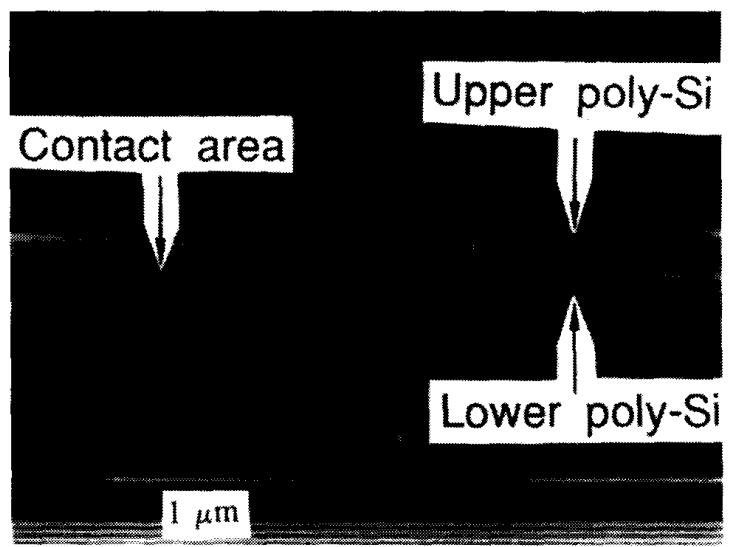

(a)

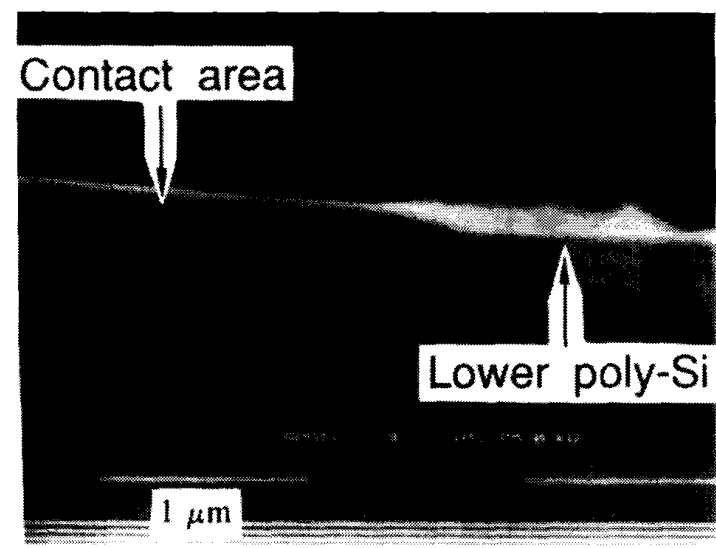

(b)

Fig. 4. SEM photographs of cross-sectional views of the double polysilicon structure for the type A of wafer group three; (a) after the nitride between the two polysilicon layers has been removed by lateral underetching using $20 \% \mathrm{HF}$, and (b) after mechanical leverage has been applied to the resulting overhanging section. The contact windows between the two polysilicon layers had previously been etched using the highly selective $\mathrm{CHF}_{3} / \mathrm{N}_{2}$ chemistry without the post-processing.

characteristics only after the applied voltage was as high as about $50 \mathrm{~V}$. After breakdown and removing the applied voltage, the insulating layer is damaged and the contact becomes permanently resistive with a contact resistance of about $300 \Omega$, which is still about two times higher than its counterparts in groups one and two. The similar contact resistance of the type B of group-three wafers compared to that of the other two groups is an indication that this insulating layer can be effectively removed by post-processing using oxygen plasma maintained in a RIE reactor in which a self-bias of $300 \mathrm{~V}$ was produced.

The fact that polymer film could not be removed in the barrel-type reactor, in which no ion bombardment takes place, suggests that high-energy ion bombardment plays a very important role in the reaction of the oxygen atoms with the carbon in the polymer film. Volatile carbon oxide would be formed, thus removing the polymer film from the polysilicon surface.

\section{Results on Mechanical AdHesion}

The two polysilicon layers exhibit good mechanical adhesion irrespective of etching chemistry applied for the nitride etching. Good mechanical adhesion is an obvious requirement for stable electrical contact. Since groups one, two, and type B of three yield good electrical contact characteristics, no problems with the mechanical adhesion between the two polysilicon layers are expected. Indeed, the double polysilicon structure was examined for its mechanical adhesion under SEM. First the nitride between the two polysilicon layers in the area other than the contact windows was removed by etching in $20 \% \mathrm{HF}$. The resulting gap between the two polysilicon layers was subjected to mechanical leverage. Both optical and SEM observation showed that no cracking had taken place at the interlayer contact due to the mechanical leverage, indicating that all the wafers have good mechanical adhesion between the two polysilicon layers. Experiments demonstrate, surprisingly, that type A of the group three, with polymer film between the two polysilicon layer, also showed a good mechanical adhesion. Fig. 4(a) shows the cross-sectional view of the double polysilicon structure for type A of group-three wafers directly after the nitride has been removed by wet etching. Fig. 4(b) shows the same structure after mechanical leverage has been carried out. It can be seen in Fig. 4(b) that the upper polysilicon layer remained fixed to the lower one in the contact area despite the breaking-off of the overhanging part of the upper polysilicon by mechanical leverage.

\section{CONCLUSION}

Effects of plasma etching chemistry and post-processing on both the mechanical adhesion and electrical contact of double polysilicon structures through contact windows in a silicon nitride layer have been examined. Three plasma etching chemistries have been used for the etching of the nitride layer to provide contact windows for the two polysilicon layers. The first one is a $\mathrm{CF}_{4}$-dominant gas mixture with $\mathrm{SF}_{6}$ and $\mathrm{O}_{2}$ addition, with which no selectivity is obtained for the nitride etching over the underlying polysilicon layer. The second one is a $\mathrm{CHF}_{3}$-based gas mixture with $\mathrm{CF}_{4}$ addition diluted by $\mathrm{He}$, which provides a selectivity of 3 . The third one is $\mathrm{CHF}_{3}$ diluted by $\mathrm{N}_{2}$, which results in a selectivity of 15 . The postprocessing, in-situ RIE $\mathrm{O}_{2}$ plasma treatment was performed after the etching. It has been found that:

1) There was little difference (less than 6\%) in the contact resistance between wafers with and without the post-processing etched with either the $\mathrm{CF}_{4} / \mathrm{SF}_{6} / \mathrm{O}_{2}$ or $\mathrm{CHF}_{3} / \mathrm{CF}_{4} / \mathrm{He}$ chemistry.

2) The contact resistance of the wafer etched with the $\mathrm{CHF}_{3} / \mathrm{N}_{2}$ chemistry without the post- processing was extremely high $\left(\sim 10^{12} \Omega\right)$, while after the post-processing it was basically the same as its counterparts etched with the other chemistries.

3) All wafers showed a good mechanical adhesion between the two polysilicon layers. 
The results indicate that:

1) No polymer film is formed on the surface of the lower polysilicon layer when the nitride layer on top is etched through with the $\mathrm{CF}_{4} / \mathrm{SF}_{6} / \mathrm{O}_{2}$ chemistry.

2) Some polymer film is formed with the $\mathrm{CHF}_{3} / \mathrm{CF}_{4} / \mathrm{He}$ chemistry, but the film is sufficiently thin or has been removed readily during the subsequent plasma ashing of the photoresist, and that the contact resistance is not significantly affected.

3) There is significant polymer film deposition on the lower polysilicon layer with the $\mathrm{CHF}_{3} / \mathrm{N}_{2}$ chemistry and the film is thick enough to actually insulate the two polysilicon layers. This polymer film could be effectively removed by using the in-situ oxygen plasma post-processing, in which high energy ion bombardment plays a very important role.

It can therefore be concluded that:

1) The $\mathrm{CF}_{4} / \mathrm{SF}_{6} / \mathrm{O}_{2}$ chemistry cannot be used for the patterning of the nitride layer due to its lack of selectivity.

2) The $\mathrm{CHF}_{3} / \mathrm{CF}_{4} / \mathrm{He}$ chemistry is most suitable in the nitride etching since it provides both reasonable selectivity and good electrical contact between the two polysilicon layers when the lower polysilicon layer is of reasonable thickness.

3) The $\mathrm{CHF}_{3} / \mathrm{N}_{2}$ chemistry can be used for the nitride patterning when very high selectivity is required, but appropriate post-processing must be carried out to ensure good electrical poly-poly contact.

\section{ACKNOWLEDGMENT}

The authors are indebted to the staff of Delft Institute of Microelectronics and Submicrontechnology (DIMES), especially Dr. P. M. Sarro and M. Laros, for their assistance during processing.

\section{REFERENCES}

[1] R. T. Howe, "Surface micromachining for microsensors and microactuators," J. Vac. Sci. Technol., vol. B6, pp. 1809-1813, 1988.

[2] M. Mehregany, S. D. Senturia, J. H. Lang, and P. Nagarkar, "Micromotor fabrication," IEEE Trans. Electron Devices, vol. ED-39, pp. 2060-2068, 1992.

[3] K. Aratani, P. J. French, P. M. Sarro, R. F. Wolffenbuttel, and S. Middelhoek, "Process and design considerations for a tuneable interferometer array in silicon," in Proc. 1993 IEEE Micro Electro Mechanical Systems (MEMS '93), pp. 230-235, 1993.

[4] D. L. Flamm, "Introduction to plasma chemistry," in Plasma Etching-an Introduction, D. M. Maros and D. L. Flamm, Ed. Lakewood, California: Academic Press, 1989, pp. 91-184.

[5] P. J. French, B. P. van Drieënhuizen, D. Poenar, J. F. L. Goosen, P. M. Sarro, and R. F. Wolffenbuttel, "Low-stress polysilicon process compatible with standard device processing," in Sensors VI Technology, System and Applications, K. T. V. Grattan and A. T. Augousti, Ed. UK: IOP Publishing, 1993, pp. 129-134.

[6] T. C. Shen, G. B. Gao, and H. Morkoc, "Recent developments in ohmic contacts for III-V compound semiconductors," J. Vac. Sci. Technol., vol. B-10, pp. 2113-2132, 1992.
17] C. J. Mogab, A. C. Adams, and D. L. Flamm, "Plasma etching of Si and $\mathrm{SiO}_{2}$ - the effect of oxygen additions to $\mathrm{CF}_{4}$ plasmas," J. Appl. Phys., vol. 49 , pp. $3796-3803,1978$.

[8] T. Enomoto, M. Denda, A. Yasuoka, and H. Nakata, "Loading effect and temperature dependence of etch rate in $\mathrm{CF}_{4}$ plasma," Jpn. J. Appl. Phys., vol. 18, pp. 155-163, 1979.

[9] H. W. Lehamn and R. Widmer, "Profile control by reactive sputter etching," J. Vac. Sci. Technol., vol. 15, pp. 319-326, 1978.

[10] J. Dulak, B. J. Howard, and C. Steinbruchel, "Etch mechanism in the reactive ion etching of silicon nitride," J. Vac. Sci. Technol., vol. A-9, pp. 775-778, 1991.

[11] T. C. Mele, J. Nulman, and J. P. Crusius, "Selective and anisotropic reactive ion etching of LPCVD silicon nitride with $\mathrm{CHF}_{3}$ based gases," J. Vac. Sci. Technol., vol. B-2, pp. 684-687, 1984.

[12] H. Norstrom, R. Buchta, F. Runovc, and P. Wiklund, "RIE of $\mathrm{SiO}_{2}$ in doped and undoped fluorocarbon plasmas," Vacuum, vol. 32, pp. $737-754,1982$.

[13] P. E. Clark, D. Field, A. J. Hydes, D. F. Klemperer, and M. J. Seakins, "Mass spectrometric studies of plasma etching of silicon nitride," $J$. Vac. Sci. Technol., vol. B-3, pp. 1614-1619, 1985.

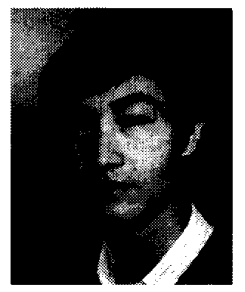

Yuan Xiong Li (S'91) received the B.Sc. degree in semiconductor physics and device physics from Hefei University of Technology, P. R. China in 1982 , and the M.Sc. degree in integrated circuit design and processing from Shanghai Institute of Mettallurgy, Academia Sinica, P. R. China in 1986, with his thesis work concerning the design and processing technology of high frequency dual gate MOSFET's.

From 1986 to 1991 , he was a research associate in the same institute, where he was engaged in research on high speed CMOS technology and ASIC design. Since September 1991 he has been at the Laboratory for Electronic Instrumentation, Department of Electrical Engineering. Delft University of Technology, working toward the Ph.D. degree on the subject of micromachining technology for sensor applications.

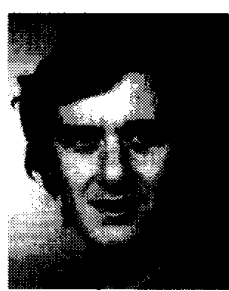

Patrick J. French received the B.Sc. degree in mathematics and the M.Sc. degree in electronics from Southampton University, UK, in 1981 and 1982, respectively. In 1986 he obtained the Ph.D. degree, also from Southampton University, which was a study of piezoresistive effect in polysilicon. After 18 months as a post-doc at Delft University, The Netherlands, he moved to Japan in 1988. For three years he worked on sensors for automotives at the Central Engineering Laboratories of Nissan Motor Company. He returned to Delft University in May 1991 and is now a staff member of the Laboratory for Electronic Instrumentation with interests in micromachining and process optimization related to sensors.

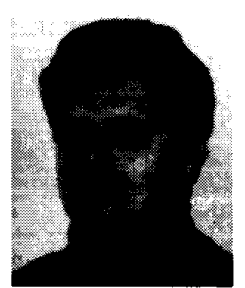

Reinoud F. Wolffenbuttel (S'86-M'88) received the M.Sc. degree in 1984 from the Delft University of Technology. In 1988 he received the Ph.D. degree on the application of silicon to color sensing.

Since 1986, he has been a staff member of the Laboratory for Electronic Instrumentation and is involved in digital instrumentation and integrated silicon smart sensors. 